\title{
Crescimento e acúmulo de macronutrientes na cultura da cebola em Baraúna (RN) e Petrolina (PE)
}

\author{
Pedro Aguiar Neto ${ }^{1}$, Leilson C. Grangeiro ${ }^{2}$, Alessandra M. S. Mendes ${ }^{3}$, Nivaldo D. Costa ${ }^{4}$, \\ Saulo de T. P. Marrocos ${ }^{5} \&$ Valdívia F. L. de Sousa ${ }^{6}$
}

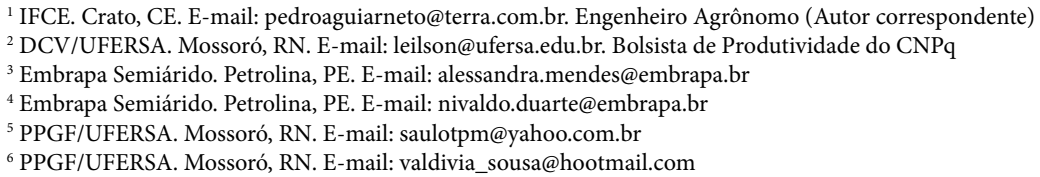

\section{Palavras-chave:} Allium cepa L. acúmulo de massa seca marcha de absorção nutrição de plantas

\begin{abstract}
R E S U M O
Com o objetivo de avaliar o crescimento e o acúmulo de nutrientes por cultivares de cebola experimentos foram desenvolvidos na estação experimental de Bebedouro (Petrolina, PE) pertencente à Embrapa Semiárido, no período de maio a outubro de 2009 e em Baraúna, RN, em área comercial, no período de junho a outubro de 2009. O delineamento utilizado em cada experimento foi em blocos casualizados completos, com quatro repetições em esquema fatorial $2 \times 6$. Os tratamentos resultaram da combinação de duas cultivares de cebola (IPA 11 e Texas Grano 502) e seis épocas de coleta (15, 30, 45, 60, 75 e 90 DAT). Em cada coleta foram utilizadas seis plantas por repetição. A cebola, cultivares IPA 11 e Texas Grano, apresentou crescimento inicial lento intensificando-o a partir dos 30 dias após o transplantio. Maiores incrementos na matéria seca total, da parte aérea e do bulbo, ocorreram no período de 60 a 75 DAT. Os nutrientes foram absorvidos pela cebola na seguinte ordem: $\mathrm{Ca}>\mathrm{K}$ $>\mathrm{N}>\mathrm{Mg}>\mathrm{P}$ e $\mathrm{Ca}>\mathrm{N}>\mathrm{K}>\mathrm{Mg}>\mathrm{P}$ para "Texas Grano 502" e "IPA 11" em Petrolina e $\mathrm{K}>\mathrm{Ca}>\mathrm{N}>\mathrm{Mg}>\mathrm{P}$ e $\mathrm{N}>\mathrm{K}>\mathrm{Ca}>\mathrm{Mg}>\mathrm{P}$ para “Texas Grano 502" e "IPA 11" em Baraúna. As cultivares Texas Grano 502 e IPA 11 exportaram mais nutrientes em Baraúna.
\end{abstract}

Key words: Allium cepa L. dry matter accumulation absorption curves plant nutrition

\section{Growth and accumulation of macronutrients in onion crop in Baraúna (RN) and Petrolina (PE)}

\begin{abstract}
A B S T R A C T
With the objective to evaluate the growth and nutrient accumulation by onion cultivars, experiments were conducted at the experimental station of Bebedouro (Petrolina, PE) of Embrapa Semiarid, during May to October 2009, and in Baraúna, RN, in commercial area, from June to October 2009. The statistical design utilized in the experiment was a randomized complete block design, RBD with four replications in a 2 x 6 factorial. Treatments were the combinations of two cultivars of onion (IPA 11 and Texas Grano 502) and six sampling times (15, 30, 45, 60, 75 and 90 days after transplanting - DAT). In each collection six plants per replication were used. The onion cultivars IPA11 and Texas Grano presented initially slow growth, increasing from 30 DAT. Greater increases in total dry mass, shoot and bulb occurred at 60-75 DAT. The nutrients were absorbed by the onion in the following order: Ca $>\mathrm{K}>\mathrm{N}>\mathrm{Mg}>\mathrm{P}$ and $\mathrm{Ca}>\mathrm{N}>\mathrm{K}>\mathrm{Mg}>\mathrm{P}$ for "Texas Grano 502" and "IPA11" in Petrolina and $\mathrm{K}>\mathrm{Ca}>\mathrm{N}>\mathrm{Mg}$ $>\mathrm{P}$ and $\mathrm{N}>\mathrm{K}>\mathrm{Ca}>\mathrm{Mg}>\mathrm{P}$ for "Texas Grano 502" and "IPA 11" in Baraúna. Cultivars Texas Grano 502 and 11 IPA exported more nutrients in Baraúna.
\end{abstract}

\section{INTRODUÇÃO}

A cebola (Allium cepa) ocupa, entre as hortaliças cultivadas, a terceira posição em importância econômica no Brasil, ficando atrás apenas da batata e do tomate (Gonçalves et al., 2009).

Sousa et al. (2008) afirmam que as cultivares das séries IPA são recomendadas para a região nordeste, onde bons níveis de produtividade foram observados nas regiões de Mossoró, RN e Petrolina, PE, com produtividades na ordem de 45,89 e 48,25 t ha ${ }^{-1}$, respectivamente.
O incremento na produtividade da cebola, tal como a melhoria na sanidade e na qualidade dos bulbos, é influenciado pela nutrição das plantas. A adição excessiva de fertilizantes, principalmente de $\mathrm{N}, \mathrm{P}$ e $\mathrm{K}$, o uso indiscriminado de corretivos de acidez e o monocultivo, são práticas comuns em regiões produtoras (Kurtz \& Ernani, 2010). Rodolfo Júnior et al. (2008) citam que adubos orgânicos não substituem os fertilizantes convencionais.

De acordo com May et al. (2008) a quantidade de nutrientes extraída pelos bulbos representa componente significativo de 
retirada de nutrientes do solo e sua avaliação deve ser utilizada para definir a quantidade de nutrientes a ser reposta no solo, por meio de programas de adubação. Portanto, a marcha de absorção das culturas é uma ferramenta imprescindível para auxiliar os programas de adubação e o manejo de fertilizantes das lavouras (Echer, 2009).

Neste contexto o objetivo do presente trabalho foi avaliar o crescimento e o acúmulo de nutrientes por cultivares de cebola em Petrolina, PE e Baraúna, RN.

\section{Material e Métodos}

Os experimentos foram desenvolvidos na estação experimental de Bebedouro (Petrolina, $\mathrm{PE}$ ) pertencente à Embrapa Semiárido, no período de maio a outubro de 2009, e em Baraúna, RN, em área comercial, no período de junho a outubro de 2009.

Em Petrolina as coordenadas geográficas do local são $09^{\circ} 09^{\prime}$ de latitude Sul e $40^{\circ} 22^{\prime}$ de longitude Oeste e altitude de 365,5 m.

O clima da região, de acordo com a classificação climática de Köppen, é do grupo BSwh (Pereira et al., 2010), isto é, quente e seco com precipitação pluviométrica bastante irregular, média anual de $808,4 \mathrm{~mm}$. O solo da estação experimental de Bebedouro (Petrolina) foi classificado como Argissolo Vermelho-Amarelo Eutrófico.

Em Baraúna as coordenadas geográficas do local são $05^{\circ} 04^{\prime}$ de latitude Sul e $37^{\circ} 37^{\prime}$ de longitude Oeste e altitude de $94 \mathrm{~m}$. O clima da região, de acordo com a classificação climática de Köppen, é do grupo BSwh, isto é, quente e seco com precipitação pluviométrica média anual de $673 \mathrm{~mm}$ concentrados em uma única estação, de fevereiro a maio, com ocorrência de períodos agudos de estiagem. A temperatura média anual é de $27,4^{\circ} \mathrm{C}$ com taxas elevadas de evapotranspiração e balanço hídrico negativo durante parte do ano e insolação muito forte $(2700 \mathrm{~h}$ ano ${ }^{-1}$ ), aliada a uma umidade relativa média anual em torno de 70\% (IDEMA, 2010).

O solo de Baraúna foi classificado como Cambissolo Háplico franco-argilo-arenoso. As análises de solo das áreas experimentais foram realizadas no laboratório de análise de solo da Embrapa Semiárido (Petrolina, PE) e no laboratório de análise de solo e água da Universidade Federal Rural do Semiárido (Mossoró, RN).

O delineamento utilizado em cada experimento foi em blocos casualizados completos, com quatro repetições em esquema fatorial $2 \times 6$. Os tratamentos resultaram da combinação de duas cultivares de cebola (IPA 11 e Texas Grano $502)$ e seis épocas de coleta $(15,30,45,60,75$ e 90 dias após o transplantio). Em cada coleta foram utilizadas seis plantas por repetição. A unidade experimental foi constituída por oito fileiras de plantas de 6,0 $\mathrm{m}$ de comprimento, espaçadas $0,10 \mathrm{x}$ $0,10 \mathrm{~m}$ perfazendo uma área total de $4,8 \mathrm{~m}^{2} \mathrm{e}$ área útil de $3,48 \mathrm{~m}^{2}$.
As coletas de plantas foram realizadas nas seis fileiras centrais, excluindo-se a primeira e última planta de cada linha.

O preparo do solo constou de uma aração a $30 \mathrm{~cm}$ de profundidade seguida de gradagem e preparo dos canteiros. A adubação de fundação foi realizada de acordo com a análise de solo e recomendação para a cultura, segundo Cavalcanti (2008), sendo utilizados, em Petrolina/PE, $36 \mathrm{~kg} \mathrm{ha}^{-1} \mathrm{de} \mathrm{N}, 144 \mathrm{~kg} \mathrm{ha}^{-1}$ de $\mathrm{P}_{2} \mathrm{O}_{5}$ e $120 \mathrm{~kg} \mathrm{ha}^{-1}$ de $\mathrm{K}_{2} \mathrm{O}$ aplicados através da formulação comercial 06-24-12.

$\mathrm{Na}$ adubação de cobertura utilizaram-se $160 \mathrm{~kg} \mathrm{ha}^{-1}$ de $\mathrm{N}$ e $120 \mathrm{~kg} \mathrm{ha}^{-1}$ de $\mathrm{K}_{2} \mathrm{O}$, nas formas de ureia, sulfato de amônio e cloreto de potássio, parcelados em quatro aplicações aos 20 , 30, 40 e 50 dias após o transplantio. Em Baraúna a fundação foi realizada com $33 \mathrm{~kg} \mathrm{ha}^{-1}$ de $\mathrm{N}$ e $132 \mathrm{~kg} \mathrm{ha}^{-1}$ de $\mathrm{P}_{2} \mathrm{O}_{5}$ na forma de MAP. A adubação de cobertura foi via água de irrigação, iniciando-se aos 12 DAT e realizada até os 60 dias após o transplante - DAT, tendo-se empregado $146 \mathrm{~kg} \mathrm{ha}^{-1}$ de N, 29,0 $\mathrm{kg} \mathrm{ha}^{-1}$ de $\mathrm{P}_{2} \mathrm{O}_{5}$ e $30 \mathrm{~kg} \mathrm{ha}^{-1}$ de $\mathrm{K}_{2} \mathrm{O}$ na forma de ureia, cloreto de potássio e das formulações comerciais KSC1 (14\% de N, 40\% de $\mathrm{P}_{2} \mathrm{O}_{5}, 5 \%$ de $\mathrm{K}_{2} \mathrm{O}, 3 \%$ de $\mathrm{S}, 0,1 \%$ de $\mathrm{B}, 0,01 \%$ de $\mathrm{Mo}, 0,1 \%$ de $\mathrm{Zn}$ e $0,05 \%$ de $\mathrm{Cu}$ ) e KSC2 ( $23 \%$ de N, $5 \%$ de $\mathrm{P}_{2} \mathrm{O}_{5}, 5 \%$ de $\mathrm{K}_{2} \mathrm{O}$, $10 \%$ de S, 0,1\% de Zn e 0,05\% de Mn).

As mudas foram produzidas em sementeiras com dimensões de $1 \mathrm{~m}$ de largura e $20 \mathrm{~cm}$ de altura, utilizando-se $10 \mathrm{~g} \mathrm{~m}^{-2} \mathrm{de}$ semente para semeadura em sulcos transversais ao comprimento do canteiro com profundidade de $0,01 \mathrm{~m}$ e distância entre sulcos de $0,10 \mathrm{~m}$. O transplantio foi realizado 45 dias após a semeadura quando as mudas atingiram 15 a $20 \mathrm{~cm}$ de altura, no espaçamento de $0,10 \times 0,10 \mathrm{~m}$ e com densidade populacional de 400.000 plantas ha ${ }^{-1}$. O sistema de irrigação utilizado foi por microaspersão em Petrolina e por gotejamento em Baraúna. A frequência de irrigação foi diária e a quantidade de água fornecida de acordo com a necessidade da cultura. O controle de plantas daninhas foi realizado aplicando-se, após quatro dias do transplantio da cebola, os herbicidas comerciais Goal e Herbadox nas doses de 0,2 e 2,0 $\mathrm{L} \mathrm{ha}^{-1}$, respectivamente.

As coletas de plantas foram realizadas nos períodos préestabelecidos, comumente na parte da manhã para evitar que as plantas murchassem até chegar ao laboratório. Foram coletadas seis plantas por período e quatro repetições, no total de vinte e quatro plantas por cultivar e cento e quarenta e quatro plantas nos seis períodos. As plantas foram acondicionadas em sacos de papel até o laboratório.

No laboratório as plantas foram separadas em folhas e bulbos, na altura de 0,01 $\mathrm{m}$ do pseudocaule, lavadas e acondicionadas separadamente em sacos de papel identificados e colocados em estufa com circulação forçada de ar na temperatura de $65^{\circ} \mathrm{C}$ até atingir massa constante. Em função da massa seca e órgãos, foi determinado o acúmulo de massa seca em cada época de coleta cujos resultados foram expressos em g planta ${ }^{-1}$; em seguida, as amostras foram processadas em moinho e acondicionadas em recipientes fechados.

Tabela 1. Resultados das análises de solo das áreas experimentais

\begin{tabular}{|c|c|c|c|c|c|c|c|c|}
\hline \multirow{2}{*}{ Experimento } & \multirow{2}{*}{$\begin{array}{c}\mathrm{pH} \\
\text { (água 1:2,5) }\end{array}$} & \multirow{2}{*}{$\frac{\mathrm{MO}}{\left(\mathrm{g} \mathrm{kg}^{-1}\right)}$} & $\mathbf{P}$ & $\mathbf{K}$ & $\mathrm{Ca}$ & $\mathrm{Mg}$ & $\mathrm{Na}$ & Al \\
\hline & & & \multicolumn{2}{|c|}{$\left(\mathrm{mg} \mathrm{dm}^{-3}\right)$} & \multicolumn{4}{|c|}{$\left(\mathrm{cmol}_{\mathrm{c}} \mathrm{dm}^{-3}\right)$} \\
\hline Petrolina & 7,4 & 13,9 & 44,5 & 700 & 1,9 & 1,5 & 0,05 & 0,05 \\
\hline Baraúna & 8,0 & 12,5 & 54,6 & 556 & 5,4 & 2,9 & 0,77 & 0 \\
\hline
\end{tabular}


As análises químicas para a determinação dos teores de nutrientes presentes em cada fração foram realizadas nos extratos obtidos pela digestão sulfúrica (nitrogênio), nítrico-perclórica (fósforo, potássio, cálcio, magnésio, zinco, ferro e manganês). $\mathrm{O}$ nitrogênio foi quantificado pelo método semi-micro Kjeldahl, fósforo pelo método do complexo fosfo-molíbdico em meio redutor adaptado por Braga \& Defelipo (1974) e o potássio por fotometria de emissão de chama. O cálcio, magnésio, ferro, zinco e o manganês, por espectrofotometria de absorção atômica (EMBRAPA, 1997).

Os resultados das análises forneceram as concentrações dos nutrientes (N, P, K, Ca e Mg) e para se determinar a quantidade desses acumulados em cada fração da planta, foi multiplicada a concentração pela massa seca da referida fração sendo que o acúmulo total na planta foi determinado através da soma do acúmulo das frações para cada nutriente.

A colheita foi realizada quando em média $60 \%$ das plantas se encontravam estalados (Vidigal et al., 2010b).

As plantas colhidas foram submetidas ao processo de cura permanecendo seis dias expostas ao sol e dois dias à sombra efetuando-se, em seguida, o corte da parte aérea com vista à determinação da produtividade total $\left(\mathrm{t} \mathrm{ha}^{-1}\right)$.

Para à análise estatística, cada experimento foi analisado individualmente com os dados sendo submetidos às análises de variância, com o software SISVAR (Ferreira, 2011) e de regressão com o software Table curve (Jandel Scientific, 1991). Na análise de regressão os modelos foram escolhidos baseados na ocorrência biológica ena significância dos coeficientes de regressão tendo, como variável independente, a idade da planta, em dias, após o transplantio.

\section{Resultados e Discussão}

O acúmulo de massa seca total e da parte aérea foi lento nos primeiros $30 \mathrm{DAT}$, intensificando-se a partir de então, fato constatado nas duas cultivares ('IPA 11' e 'Texas Grano 502') e nos dois locais de estudo (Petrolina e Baraúna). Após este período há um aumento significativo na massa seca da planta inteira atingindo o máximo estimado para 'IPA 11' aos 83 DAT e para 'Texas Grano 502' aos 73 DAT em Petrolina e Baraúna, respectivamente (Figuras 1A, B, C e D). Santos et al. (2007)
A.

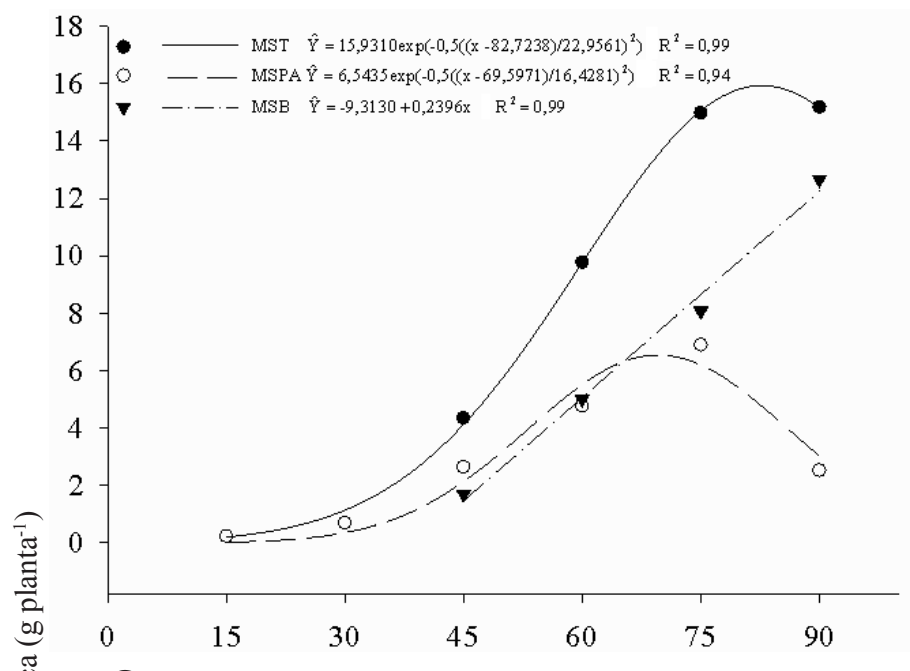

的

芯

2

C.

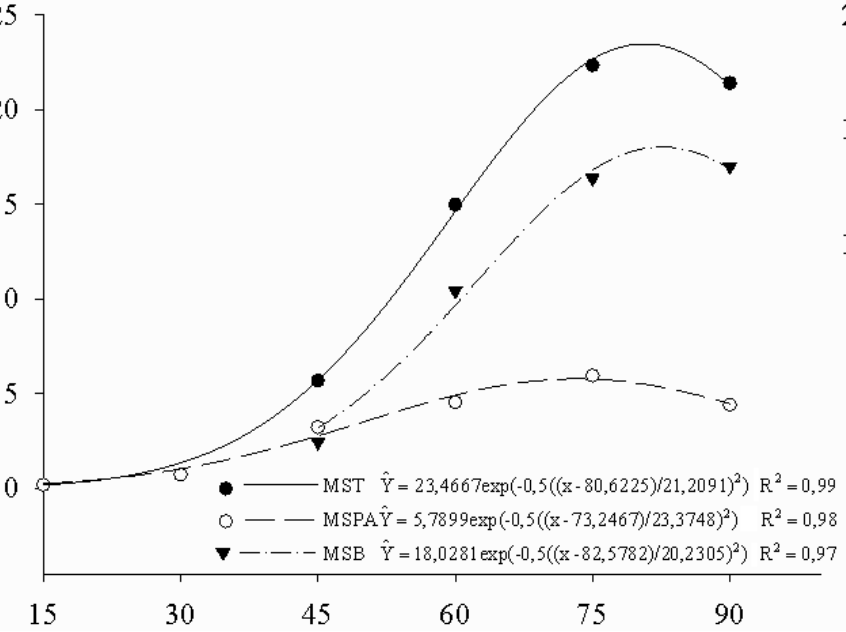

B.

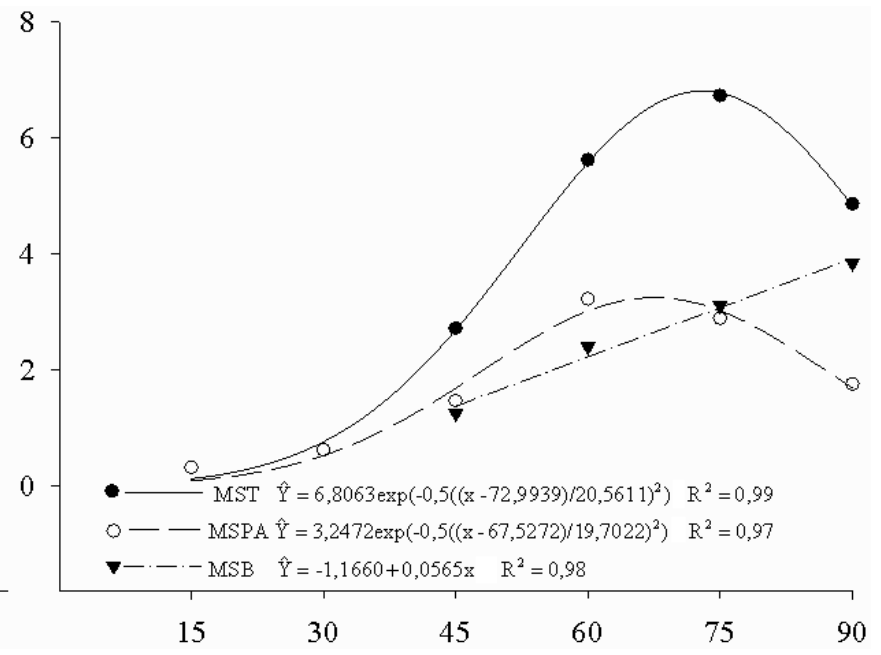

D.

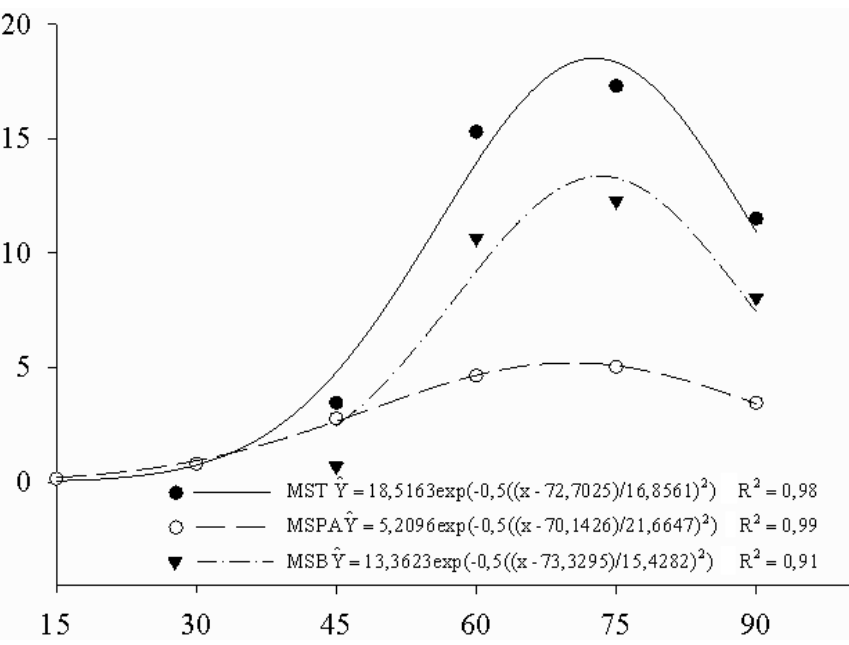

Dias após o transplantio

Figura 1. Acúmulo de Massa Seca Total (MST), Massa Seca Parte Aérea (MSPA) e Massa Seca do Bulbo (MSB) em cebola, cultivares IPA 11 (A) e Texas Grano 502 (B) em Petrolina-PE e cultivares IPA 11 (C) e Texas Grano 502 (D) em Baraúna-RN 
observaram que o acúmulo de massa seca foi lento até aos 40 DAT na cultivar "Alfa Tropical” de cebola, período após o qual ocorre um aumento significativo no teor da massa seca da planta inteira, atingindo $12,33 \mathrm{~g}$ de matéria seca planta ${ }^{-1}$ aos 80 DAT.

A cultivar IPA 11, independentemente do local, acumulou mais massa seca que a Texas Grano 502; este melhor desempenho da cultivar IPA 11 se deve ao fato da mesma ter sido desenvolvida e adaptada às condições semiáridas do nordeste brasileiro. Diferente da “Texas Grano 502" que é um material americano introduzido na região e cultivado desde o final da década de 70 (Santos \& Oliveira, 2011).

$\mathrm{O}$ acúmulo máximo de massa seca estimado no bulbo ocorreu respectivamente para "IPA 11" e "Texas Grano 502" aos 90 DAT em Petrolina (Figuras 1A e B) e aos 83 DAT e 72 DAT em Baraúna (Figuras 1C e D).

$\mathrm{O}$ acúmulo de nitrogênio $(\mathrm{N})$ na planta inteira e de nitrogênio total (NT), foi crescente sendo que o máximo estimado variou conforme o local do experimento e a cultivar de cebola. Os máximos estimados foram para "IPA 11" e "Texas Grano 502" de 330,7 mg planta-1 (78 DAT) e 155,0 mg planta ${ }^{-1}$

A.

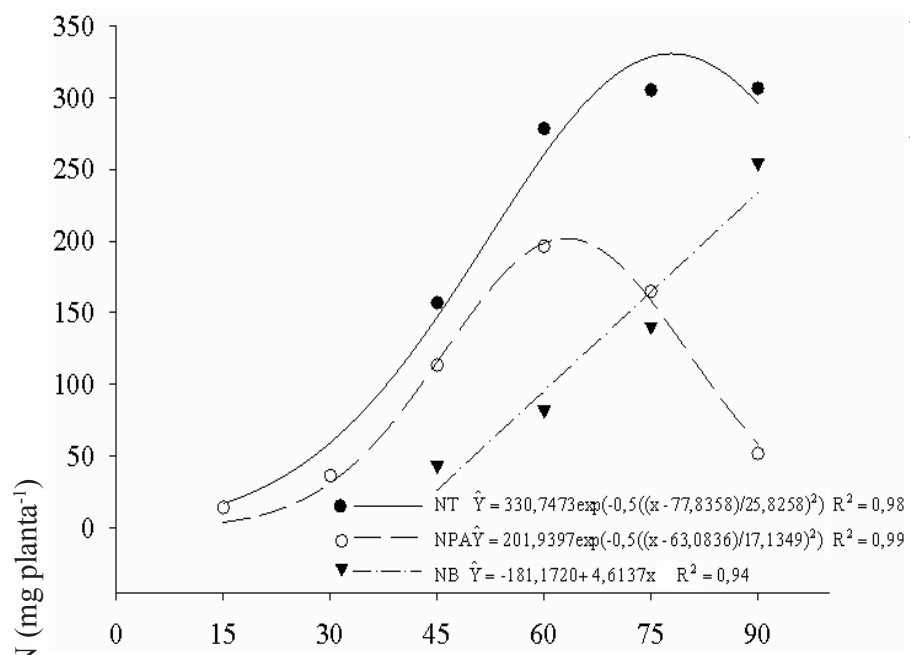

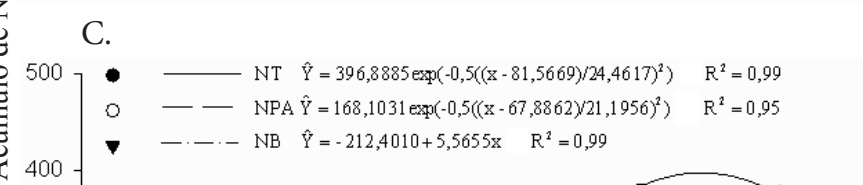

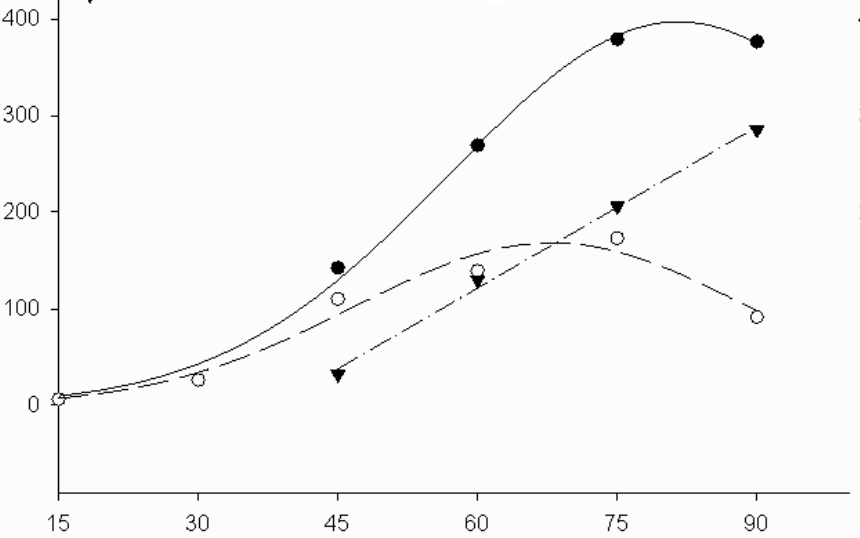

(70 DAT) em Petrolina (Figuras 2A e B) e 397,0 mg planta ${ }^{-1}$ (82 DAT) e 346,4 mg planta ${ }^{-1}$ (72 DAT) em Baraúna (Figuras $2 \mathrm{C}$ e D). A maior demanda ocorreu no período de 45 a 60 DAT (Estádio de Bulbificação), com taxas médias de acúmulo respectivamente para "IPA 11" e "Texas Grano 502" de 8,46 e 13,65 mg planta ${ }^{-1} \mathrm{~d}^{-1}$ em Baraúna (Figuras $2 \mathrm{C}$ e D) e de $8,10 \mathrm{e}$ 3,88 $\mathrm{mg}_{\text {planta }} \mathrm{d}^{-1}$ em Petrolina (Figuras $2 \mathrm{~A} \mathrm{e} \mathrm{B}$ ).

Porto et al. (2006) trabalharam com o híbrido de cebola Optima com uma densidade de plantio de 420.000 plantas $\mathrm{ha}^{-1} \mathrm{e}$ obtiveram uma produtividade de $70 \mathrm{t} \mathrm{ha}^{-1} \mathrm{e}$ o acúmulo de nitrogênio foi de $159 \mathrm{mg}$ planta $^{-1}$. A quantidade menor de nitrogênio acumulada pelo híbrido de cebola Optima em relação aos obtidos no presente trabalho com as cultivares IPA 11 e Texas Grano 502, demonstra que, embora as condições edafoclimáticas dos experimentos tenham sido diferentes, o híbrido foi mais eficiente na sua utilização. Como na planta inteira (NT) o acúmulo de $\mathrm{N}$ na parte aérea (NPA) foi crescente sendo que o máximo estimado variou conforme o experimento e a cultivar de cebola. Os máximos estimados foram, respectivamente, para "IPA 11" e “Texas Grano 502" de

B.
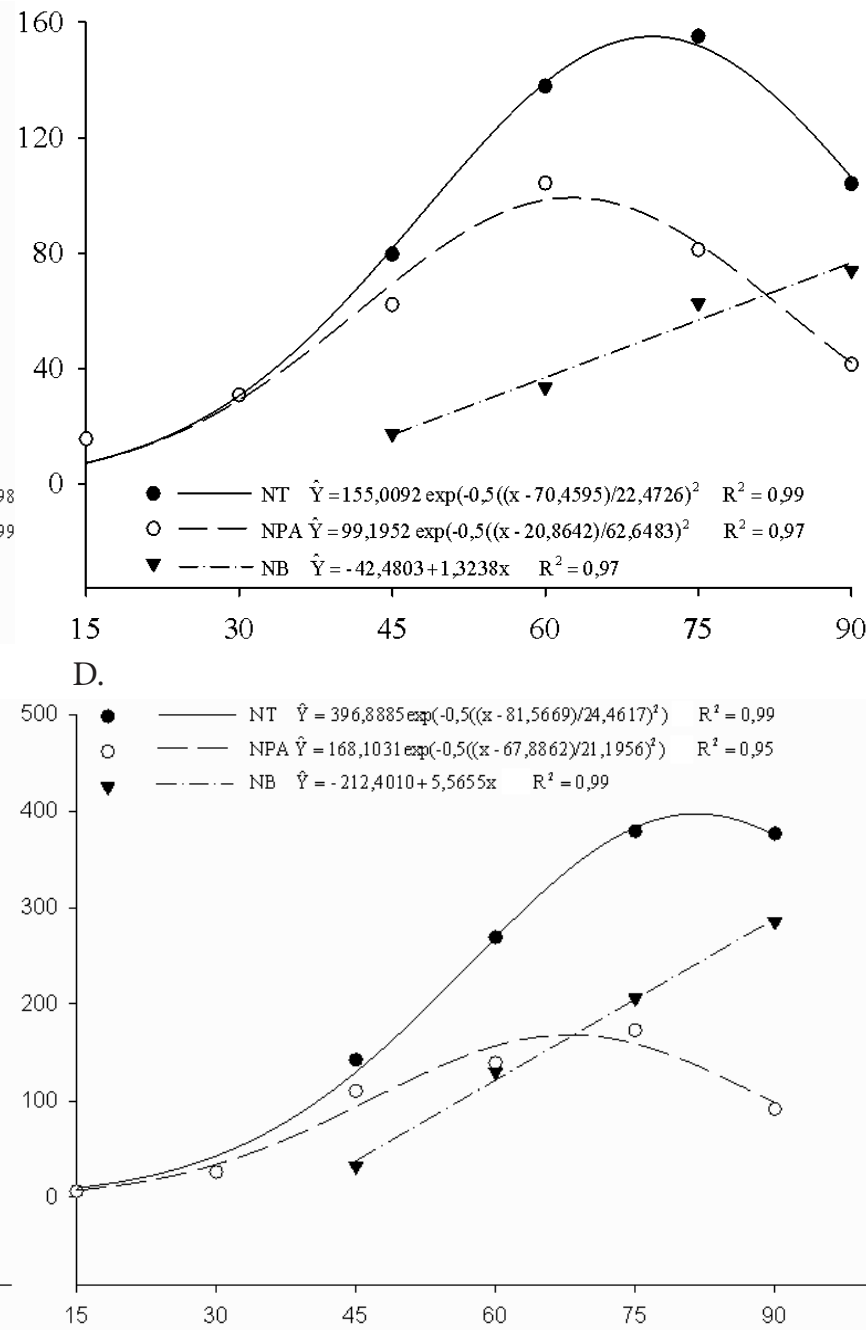

Dias após o transplantio

Figura 2. Acúmulo de Nitrogênio Total (NT), Nitrogênio na Parte Aérea (NPA) e Nitrogênio no Bulbo (NB) em cebola cultivares IPA 11 (A) e Texas Grano 502 (B) em Petrolina-PE e cultivares IPA 11 (C) e Texas Grano 502 (D) em Baraúna-RN 
201,94 e 99,20 mg planta $^{-1}$ (63 DAT) em Petrolina (Figuras 2A e B) e $168,10 \mathrm{mg} \mathrm{planta}^{-1}$ (68 DAT) e 150,95 $\mathrm{mg} \mathrm{planta}^{-1}$ (65 DAT) em Baraúna (Figuras 2C e D). A maior demanda ocorreu no período de 30 a 45 DAT (Estádio Vegetativo), com taxas médias de acúmulo respectivamente para "IPA 11" e "Texas Grano 502" de 5,60 e 4,33 $\mathrm{mg} \mathrm{planta}^{-1} \mathrm{~d}^{-1}$ em Baraúna (Figuras 2C e D). E de 5,53 e 2,80 mg planta ${ }^{-1} \mathrm{~d}^{-1}$ em Petrolina (Figuras 2A e B), no período de 45 a 60 DAT (Estádio de Bulbificação). A diferença nos períodos de demanda é devida, provavelmente, à forma como foi realizada a adubação de cobertura nos experimentos. Em Baraúna a aplicação de fertilizantes diária via água de irrigação tornou o processo de absorção de nutrientes pela planta mais eficiente haja vista que os mesmos foram aplicados nos locais de maior absorção e prontamente acessíveis às plantas. Já em Petrolina a aplicação via solo, parcelada em quatro aplicações, os nutrientes não estão prontamente disponíveis como na fertirrigação diária o que, de certa forma, fez com que o período de maior demanda em Petrolina ocorresse após o experimento de Baraúna.

A.

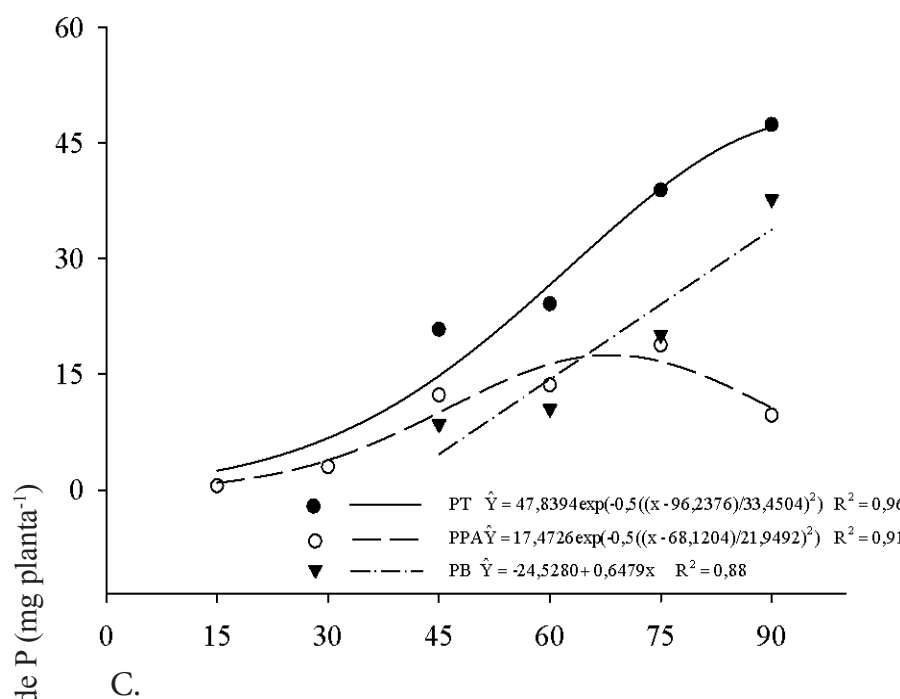

을 16 PT $\hat{\mathrm{Y}}=13,7395 \exp \left(-0,5((\mathrm{x}-82,4300) / 24,2005)^{2}\right) \quad \mathrm{R}^{2}=0,99$

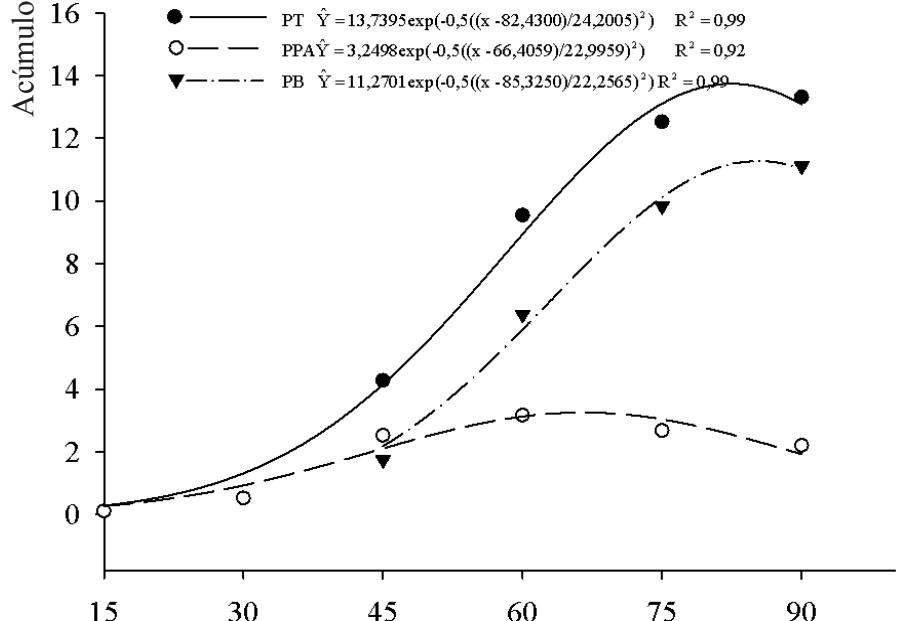

No final do ciclo houve redução no acúmulo de $\mathrm{N}$ da parte aérea, de 83 e 60\% respectivamente para "IPA 11" e "Texas Grano 502" em Petrolina (Figuras 2A e B) e de 76 e 68\% em Baraúna (Figuras 2C e D).

$\mathrm{O}$ acúmulo máximo de $\mathrm{N}$ estimado no bulbo ocorreu, respectivamente, para "IPA 11 e "Texas Grano 502" aos 90 DAT (254,48 mg planta $\left.^{-1}\right)$ e (74,40 mg planta $\left.^{-1}\right)$ em Petrolina (Figuras $2 \mathrm{~A} \mathrm{e} \mathrm{B})$ e 90 DAT $\left(283,86 \mathrm{mg}\right.$ planta $\left.^{-1}\right)$ e 74 DAT $(197,89 \mathrm{mg}$ planta $^{-1}$ ) e em Baraúna (Figuras 2C e D).

O processo de bulbificação (45 a 90 DAT) da cebola estabeleceu uma demanda elevada por nitrogênio podendose inferir, a partir das curvas de acúmulo, que houve forte translocação deste nutriente da parte aérea para o bulbo.

Independente da cultivar e do local, o fósforo $(\mathrm{P})$ foi o macronutriente acumulado em menor quantidade. Em Petrolina os valores máximos estimados de acúmulo de fósforo total (PT) foram obtidos aos 90 e $80 \mathrm{DAT}$, sendo de 47,00 e 18,33 $\mathrm{mg} \mathrm{planta}^{-1}$, respectivamente, para as cultivares IPA 11 e Texas Grano 502 (Figuras 3A e B) . Na mesma ordem, em Baraúna de 13,74 mg

B.

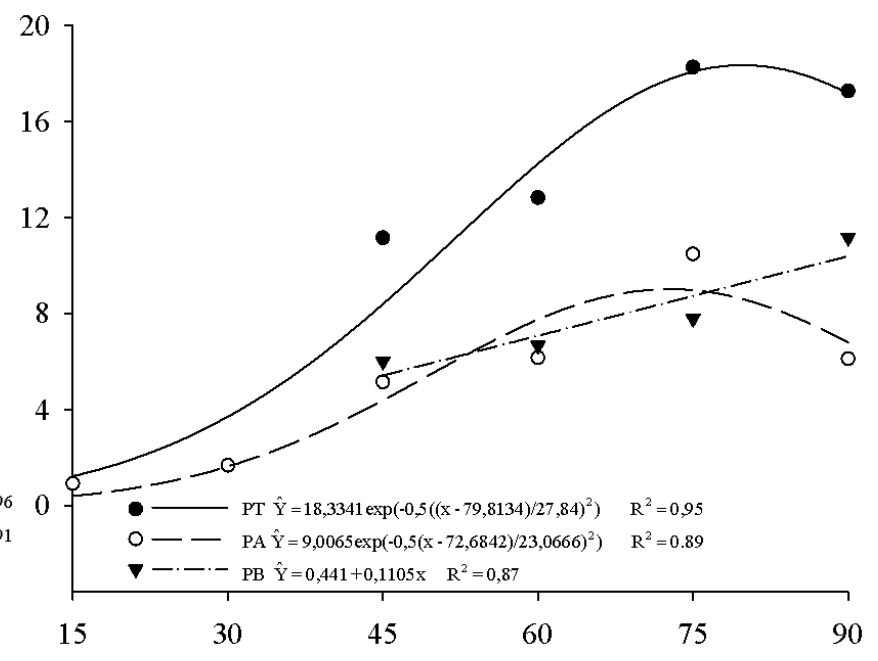

D.

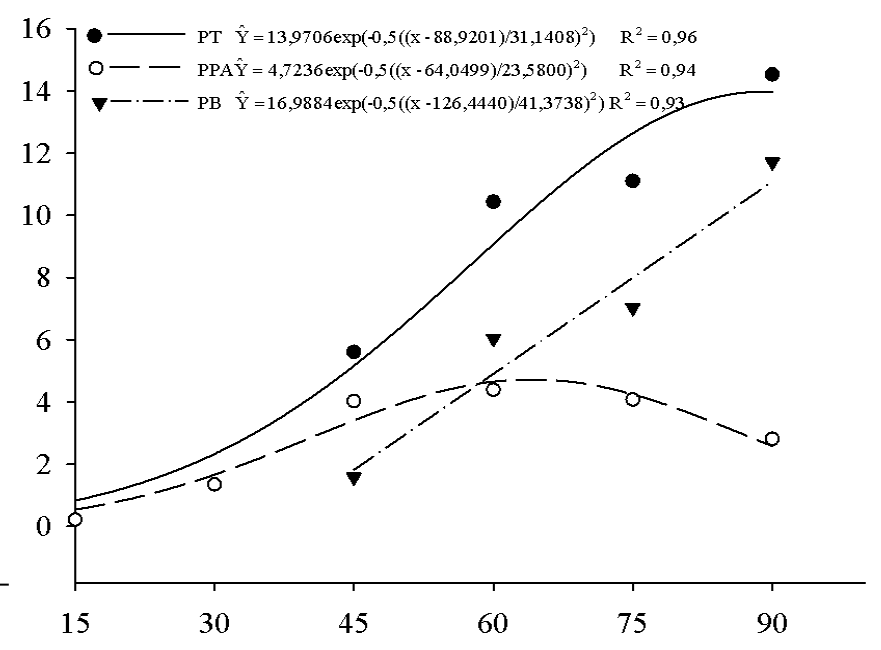

Dias após o transplantio

Figura 3. Acúmulo de Fósforo Total (PT), Fósforo na Parte Aérea (PPA) e Fósforo no Bulbo (PB) em cebola, cultivares IPA 11 (A) e Texas Grano 502 (B) em Petrolina-PE e cultivares IPA 11 (C) e Texas Grano 502 (D) em Baraúna-RN 
planta $^{-1}$ (82 DAT) e 13,97 $\mathrm{mg}$ planta $^{-1}$ (89 DAT) (Figuras 3C e D). A maior demanda ocorreu no período de 30 a 75 DAT em Petrolina e de 30 a 60 DAT em Baraúna. O acúmulo de P na parte aérea variou conforme o experimento e as cultivares de cebola. Os máximos estimados foram para "IPA 11" e "Texas Grano 502" de 17,47 mg planta-1 (68 DAT) e 9,0 mg planta ${ }^{-1}$ (73 DAT) em Petrolina (Figuras 3A e B) e 3,25 $\mathrm{mg}$ planta $^{-1}$ (66 DAT) e 4,72 mg planta $^{-1}$ (64 DAT) em Baraúna (Figuras 3C e D).

A maior demanda foi verificada no período de 30 a 45 DAT, com taxas médias de acúmulo respectivamente para "IPA 11" e “Texas Grano 502" de 0,62 e 0,23 mg planta ${ }^{-1} \mathrm{~d}^{-1}$ em Petrolina e 0,13 e 0,18 mg planta $^{-1} \mathrm{~d}^{-1}$ em Baraúna (Figuras 3A, B, C e D). No final do ciclo houve redução no acúmulo de $\mathrm{P}$ da parte aérea, de 80 e 65\%, respectivamente, para "IPA 11" e “Texas Grano 502" em Petrolina (Figuras 3A e 3B) e de 83 e $81 \%$ em Baraúna (Figuras 3C e D).

Nas cultivares IPA 11 e Texas Grano 502, o acúmulo máximo de $\mathrm{P}$ estimado no bulbo ocorreu, respectivamente, aos 90 DAT (37,29 $\left.\mathrm{mg} \mathrm{planta}^{-1}\right)$ e $\left(11,11 \mathrm{mg} \mathrm{planta}^{-1}\right)$, em Petrolina (Figuras $3 \mathrm{~A}$ e $3 \mathrm{~B})$, e 85 DAT $\left(11,27 \mathrm{mg} \mathrm{planta}^{-1}\right)$ e 90 DAT $(11,30 \mathrm{mg}$ planta $^{-1}$ ) em Baraúna (Figuras $3 \mathrm{C}$ e D). A maior demanda

A.

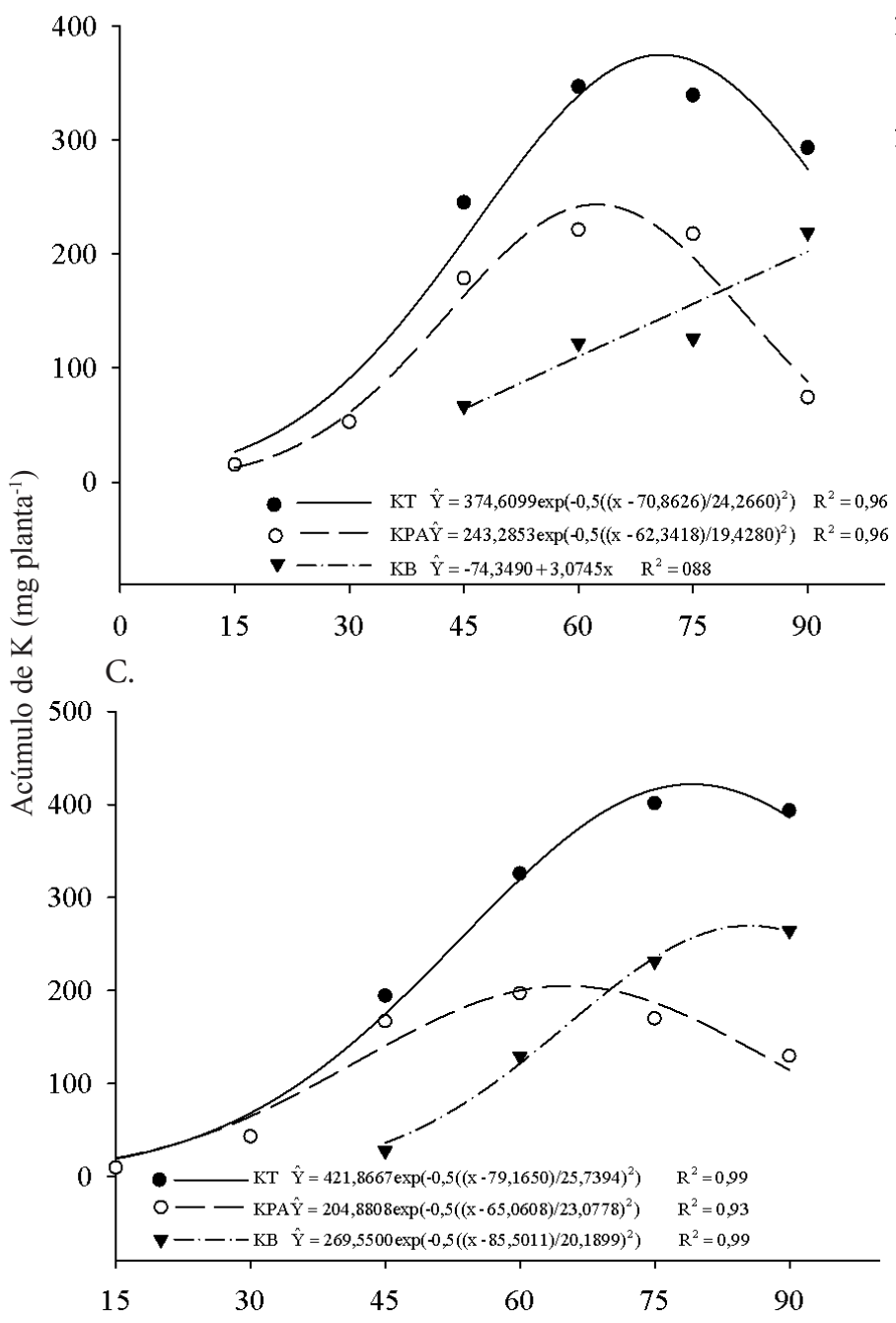

ocorreu no período de 75 a 90 DAT, com taxas médias de acúmulo para "IPA 11" e "Texas Grano 502" de 1,20 e 0,22 mg planta $^{-1} \mathrm{~d}^{-1}$ em Petrolina (Figuras $3 \mathrm{~A}$ e B). Em Baraúna a cultivar IPA 11 teve a maior taxa de acúmulo de $0,31 \mathrm{mg}_{\text {planta }}{ }^{-1} \mathrm{~d}^{-1}$ no período de 45 a 60 DAT e $0,31 \mathrm{mg}$ planta $\mathrm{d}^{-1} \mathrm{~d}^{-1}$ no período de 75 a 90 DAT na Texas Grano (Figuras $3 \mathrm{~A}$ e B).

Pôrto et al. (2006) observaram, estudando o crescimento e o acúmulo de nutrientes pela cebola "Optima" estabelecida por semeadura direta, que o fósforo foi o macronutriente acumulado em menor quantidade, 21,18 mg planta $^{-1}$, aos 150 DAS; o período de maior acúmulo para este nutriente foi de 70 a 130 DAS. De acordo com os valores observados a participação do bulbo no acúmulo total de $\mathrm{P}$ foi de aproximadamente $61 \%$ enquanto a parte aérea contribuiu com cerca de $39 \%$ do P. Resultados semelhantes foram obtidos para o $\mathrm{P}$ nos dois locais para cebola.

O potássio $(\mathrm{K})$ foi o nutriente acumulado em maior quantidade pela cebola em Baraúna, em que os máximos acúmulos totais estimados nas cultivares IPA 11 e Texas Grano 502 foram, aos 79 e 86 DAT, 421,87 e 790,50 mg planta ${ }^{-1}$, respectivamente (Figuras 4C e D), em Petrolina aos 71 e 68 DAT foi 374,61 e 218,21 $\mathrm{mg}_{\text {planta }}{ }^{-1}$, respectivamente (Figuras

B.

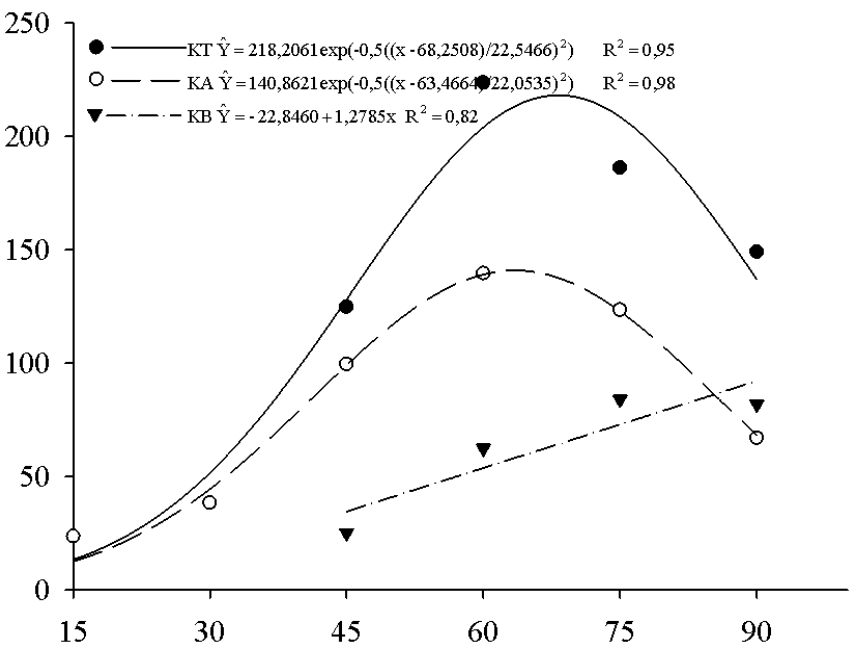

D.

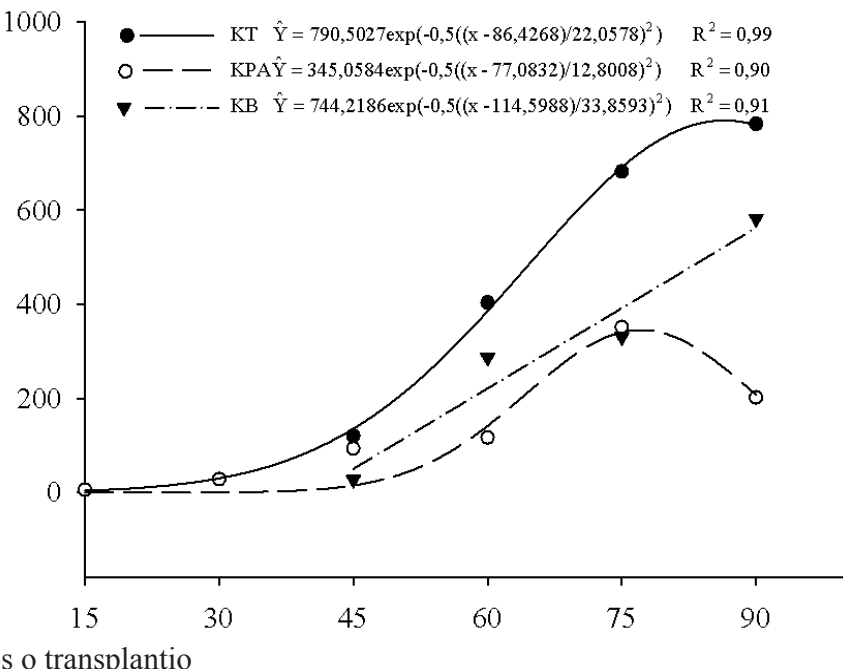

Dias após o transplantio

Figura 4. Acúmulo de Potássio Total (KT), Potássio na Parte Aérea (KPA) e Potássio no Bulbo (KB) em cebola, cultivares IPA 11 (A) e Texas Grano 502 (B) em Petrolina-PE e cultivares IPA 11 (C) e Texas Grano 502 (D) em Baraúna-RN 
4A e B). Vidigal et al. (2010b), trabalhando também com cebola observaram que $\mathrm{o} \mathrm{K}$ foi o nutriente mais absorvido pela planta de cebola, acumulando $228,25 \mathrm{mg}_{\text {planta }}{ }^{-1}$.

O acúmulo de potássio pela planta de cebola ocorreu de maneira semelhante ao acúmulo de massa seca, também observado por Porto et al. (2006; 2007). Assim como constatado para a maioria das hortaliças e para os híbridos Optima (Porto et al., 2006) e Superex (Porto et al., 2007), o K foi o nutriente mais absorvido.

$\mathrm{O}$ acúmulo de $\mathrm{K}$ na parte aérea (NPA) foi crescente com os máximos estimados para "IPA 11" e "Texas Grano 502" de 243,29 mg planta ${ }^{-1}$ (62 DAT) e 140,86 mg planta ${ }^{-1}$ (63 DAT), em Petrolina (Figuras 4A e B) e 204,88 mg planta ${ }^{-1}$ (65 DAT) e 345,00 mg planta ${ }^{-1}$ (77 DAT), em Baraúna (Figuras 4C e D). A maior demanda ocorreu no período de 30 a $45 \mathrm{DAT}$, com taxas médias de acúmulo respectivamente para "IPA 11" e "Texas Grano 502" de 8,4 e 4,1 mg planta ${ }^{-1} \mathrm{~d}^{-1}$ em Petrolina e de 8,3 mg planta ${ }^{-1} \mathrm{~d}^{-1}$ na "IPA 11 " no mesmo período em Baraúna e no período de 60 a 75 DAT para a “Texas Grano 502” em Baraúna com 15,6 mg planta ${ }^{-1} \mathrm{~d}^{-1}$.

A.

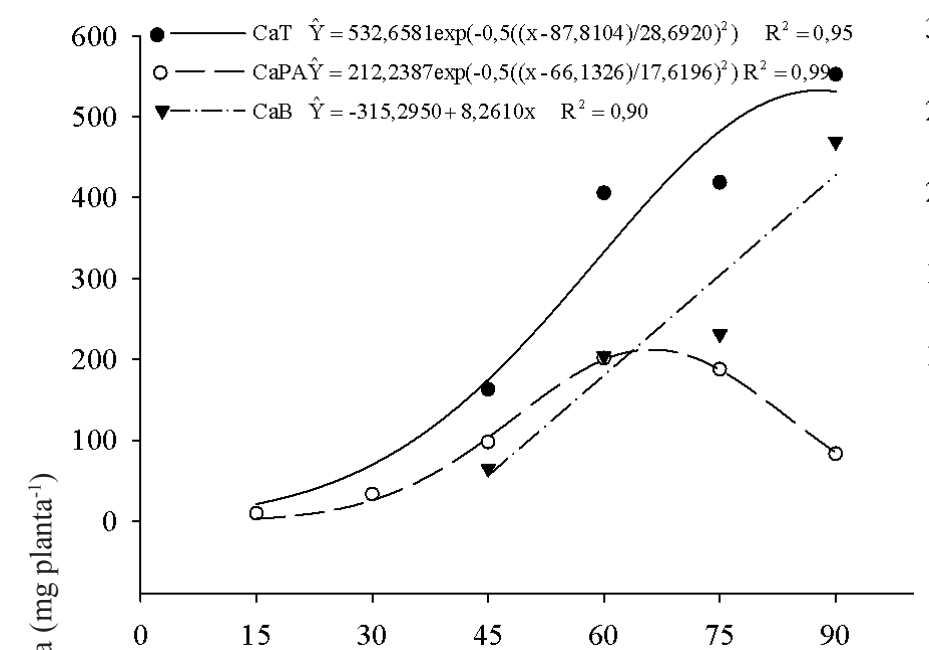

C.

$600-$ CaT $\hat{\mathrm{Y}}=532,6581 \exp \left(-0,5((\mathrm{x}-87,8104) / 28,6920)^{2}\right) \quad \mathrm{R}^{2}=0,95$

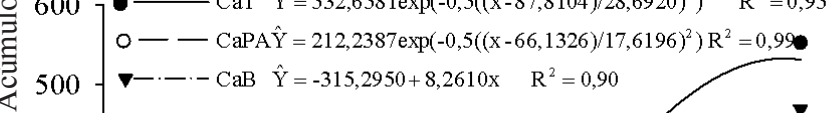

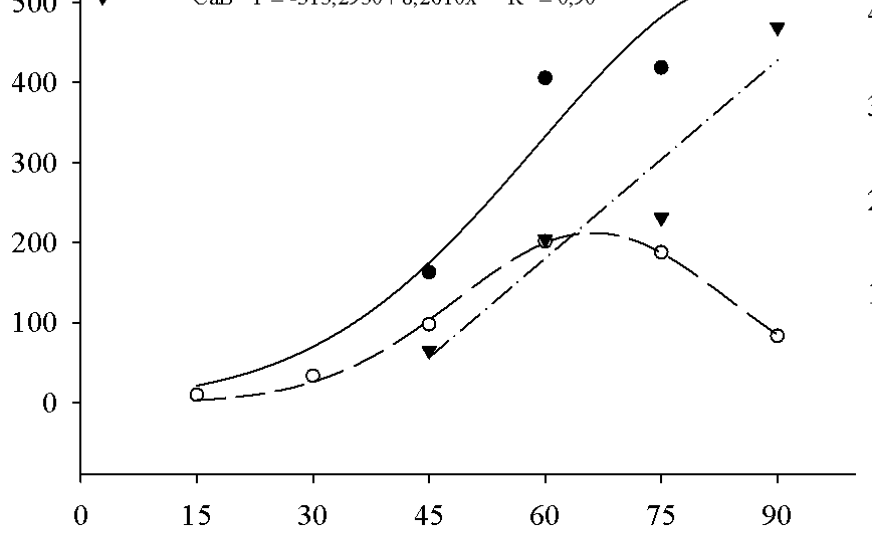

Os máximos acúmulos estimados de $\mathrm{K}$ no bulbo foram observados na "IPA 11" e "Texas Grano 502" em Baraúna com 269,55 mg planta ${ }^{-1}$ (85 DAT) e 562,42 mg planta ${ }^{-1}$ (90 DAT) (Figuras 4C e D) 75, 55\% do total, para "IPA 11" e "Texas Grano 502", em Petrolina (Figuras 4A e B) e 67 e 74\% do total, respectivamente, em Baraúna (Figuras $4 \mathrm{C}$ e D). As maiores demandas de K pelo bulbo se situaram no período de 75 a 90 DAT para IPA 11 com taxa de $6,22 \mathrm{mg}$ planta d ${ }^{-1}, 45$ a 60 DAT em "Texas Grano 502" com taxa de 2,50 mg planta-1 $\mathrm{d}^{-1}$, em Petrolina (Figuras 4A e B), e 60 a 75 DAT e 45 a 60 DAT, com taxa de 6,84 e 17,29 mg planta ${ }^{-1}$, respectivamente, para "IPA 11" e “Texas Grano 502” em Baraúna (Figuras 4C e D).

Porto et al. (2006) observaram, com a cebola "Optima", que o potássio foi o nutriente acumulado em maior quantidade, 272,74 mg planta $^{-1}$. Considerando os valores observados do total de potássio acumulado ao final do ciclo da cultura conclui-se que o bulbo contribuiu com aproximadamente $65 \%(164,14$ mg planta $\left.^{-1}\right)$.

$\mathrm{O}$ Ca foi o nutriente de maior acúmulo no experimento de Petrolina nas duas cultivares; em Baraúna o Ca se situou

B.

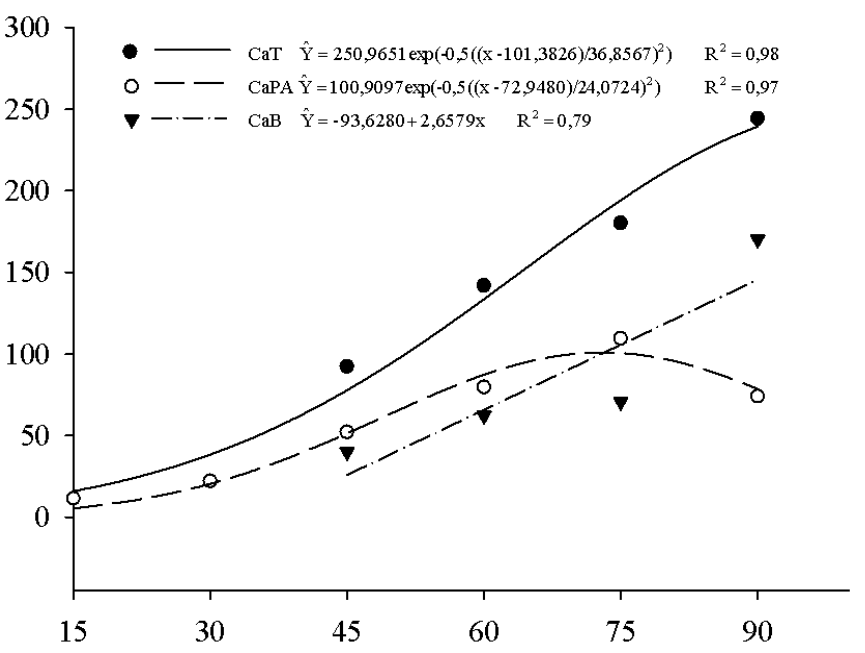

D.

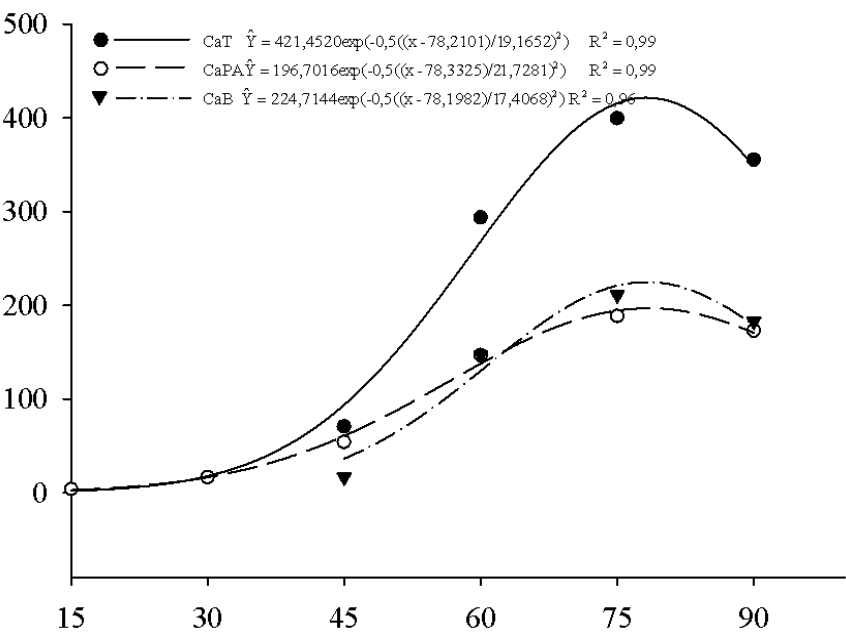

Dias após o transplantio

Figura 5. Acúmulo de Cálcio Total (CaT), Cálcio na Parte Aérea (CaPA) e Cálcio no Bulbo (CaB) em cebola, cultivares IPA 11 (A) e Texas Grano 502 (B) em Petrolina-PE ecultivares IPA 11 (C) e Texas Grano 502 (D) em Baraúna-RN 
como segundo e terceiro para a 'Texas Grano 502' e 'IPA 11', respectivamente. Os acúmulos máximos estimados foram para

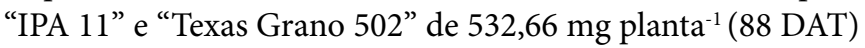
e 239,87 $\mathrm{mg}_{\text {planta }}{ }^{-1}$ (90 DAT) em Petrolina (Figuras 5A e B) e 237,0 mg planta ${ }^{-1}$ (80 DAT) e 421,45 $\mathrm{mg} \mathrm{planta}^{-1}$ (78 DAT) em Baraúna (Figuras 5C e D).

Vidigal et al. (2010a) observaram, em pesquisa na qual o $\mathrm{Ca}$ foi o terceiro nutriente mais acumulado pela planta inteira atingindo valores estimados expressos em mg planta $^{-1}$, de 88,79 de $\mathrm{Ca}$, valor bem inferior ao encontrado nesta pesquisa.

A maior demanda ocorreu no período de 45 a 60 DAT, com taxas médias de acúmulo para "IPA 11 " de 16,19 mg planta $^{-1}$ $\mathrm{d}^{-1}$, para “Texas Grano 502" no período de 30 a 45 DAT, com taxa de 4,67 mg planta $^{-1} \mathrm{~d}^{-1}$ em Petrolina (Figuras 5A e B) e de $7,70 \mathrm{mg}$ planta $^{-1} \mathrm{~d}^{-1}$, no período de 60 a 75 DAT para "IPA 11 " e 14,86 $\mathrm{mg}_{\text {planta }}{ }^{-1} \mathrm{~d}^{-1}$, no período de 45 a 60 DAT, para “Texas Grano 502” em Baraúna (Figuras 5C e D).

A quantidade de $\mathrm{Ca}$ acumulado na parte aérea variou conforme o experimento e as cultivares de cebola. Os máximos estimados foram para "IPA 11" e “Texas Grano 502" de 212,24 mg planta ${ }^{-1}$ (66 DAT) e 100,91 mg planta-1 (73 DAT) em Petrolina (Figuras 5A e 5B) e 136,88 $\mathrm{mg} \mathrm{planta}^{-1}$ (85 DAT) e 196,7 mg planta $^{-1}$ (78 DAT) em Baraúna (Figuras 5C e D). A maior demanda ocorreu no período de 45 a 60 DAT com taxas médias de acúmulo para "IPA 11" de 6,19 e 2,0 mg planta ${ }^{-1} \mathrm{~d}^{-1}$ para “Texas Grano 502", no período de 30 a 45 DAT em Petrolina (Figuras 5A e B) e de 3,50 mg planta ${ }^{-1} \mathrm{~d}^{-1}$ para "IPA 11 " no período de 60 a 75 DAT e 6,17 mg planta $^{-1} \mathrm{~d}^{-1}$ para “Texas Grano 502 ” no período de 45 a 60 DAT em Baraúna (Figuras 5C e D).

$\mathrm{O}$ acúmulo máximo de $\mathrm{Ca}$ estimado no bulbo ocorreu, respectivamente, para as cultivares "IPA 11" e "Texas Grano 502" aos 90 DAT (428,20 mg planta $\left.^{-1}\right)$ e $\left(168,83\right.$ mg planta $\left.^{-1}\right)$ em Petrolina (Figuras 5A e B) e aos 77 DAT (108,98 $\left.\mathrm{mg} \mathrm{planta}^{-1}\right)$ e $\left(224,71 \mathrm{mg} \mathrm{planta}^{-1}\right)$ aos 78 DAT, respectivamente, em Baraúna (Figuras 5C e D). As maiores demandas de Ca pelo bulbo se situaram no período de 75 a 90 DAT para "IPA 11" e "Texas Grano 502" em Petrolina (Figuras 5A e B) com taxa de 15,87 e 6,63 $\mathrm{mg}_{\text {planta }}{ }^{-1} \mathrm{~d}^{-1}$, respectivamente, e nos períodos 60 a 75 DAT e 45 a 60 DAT com taxa de 4,18 e 8,70 mg planta $^{-1} \mathrm{~d}^{-1}$ para "IPA 11" e “Texas Grano 502" em Baraúna (Figuras 5C e D) A cultivar IPA 11, exceto em Baraúna, acumulou uma quantidade maior de cálcio no bulbo no final do ciclo; este resultado foi diferente dos encontrados na literatura considerandose que o Ca se acumula em maior quantidade no bulbo em função da sua baixa mobilidade da planta. Porto et al. (2005) observaram, avaliando o acúmulo e a exportação de nutrientes pela cultivar Alfa Tropical, em MG, e pelo híbrido Optima, em SP, respectivamente, que o percentual de Ca acumulado pelos bulbos ficou próximo a 39,5\% do total acumulado pela planta por ocasião da colheita. Segundo os autores, este padrão de distribuição do Ca é resultado da redistribuição do nutriente ser praticamente nula.

O magnésio $(\mathrm{Mg})$ foi um dos macronutrientes absorvidos em menor quantidade pela planta da cebola com acúmulo máximo estimado de $\mathrm{Mg}$ total (MgT) obtido aos 90 e $72 \mathrm{DAT}$, sendo de 112,36 e $35,61 \mathrm{mg}$ planta $^{-1}$, respectivamente, para as cultivares “IPA 11" e “Texas Grano 502” em Petrolina (Figuras 6A e B). Na mesma ordem, em Baraúna, de 44,90 mg planta ${ }^{-1}$ (80 DAT) e 93,32 mg planta $^{-1}$ (75 DAT) (Figura 6C e D). Como observado nesta pesquisa, Vidigal et al. (2010b) e Porto et al. (2006; 2007) ressaltam, trabalhando com os híbridos Optima e Superex, que o $\mathrm{Mg}$ foi o macronutriente absorvido em menor quantidade atingindo valores estimados de 20,68 em mg planta ${ }^{-1}$. Segundo Sá et al. (2010) a disponibilidade de magnésio no solo é extremamente afetada pela presença de outros cátions, como potássio e cálcio. A maior demanda ocorreu no período de 60 a 75 DAT com taxa de 2,61 mg planta ${ }^{-1} \mathrm{~d}^{-1}$ para “ IPA 11 " e 45 a 60 DAT com taxa de $0,86 \mathrm{mg}$ planta ${ }^{-1} \mathrm{~d}^{-1}$ para “Texas Grano 502” em Petrolina (Figuras 6A e B). Em Baraúna as maiores demandas foram verificadas nos períodos de 60 a 75 DAT e 45 a 60 DAT com taxa de 1,15 e 4,0 mg planta ${ }^{-1} \mathrm{~d}^{-1}$ para "IPA 11 " e “Texas Grano 502”, respectivamente (Figuras 6C e D).

$\mathrm{O}$ acúmulo de $\mathrm{Mg}$ na parte aérea (MgPA) foi crescente variando com o experimento e a cultivar de cebola, sendo que os máximos estimados foram para "IPA 11" e "Texas Grano 502" de 24,35 mg planta-1 (67 DAT) e 16,67 mg planta m $^{-1}$ (65 DAT) em Petrolina (Figuras 6A e 6B) e 22,49 $\mathrm{mg} \mathrm{planta}^{-1}$ (79 DAT) e 41,32 mg planta ${ }^{-1}$ (70 DAT) em Baraúna (Figura 6C e D). A maior demanda ocorreu nos períodos de 30 a 45 DAT e 45 a 60 DAT, com taxas médias de acúmulo respectivamente para "IPA 11" e “Texas Grano 502" de 0,89 e 0,47 $\mathrm{mg}^{\text { planta }}{ }^{-1} \mathrm{~d}^{-1}$ em Petrolina (Figuras 6A e B). E de 0,53 e 1,82 mg planta $^{-1} \mathrm{~d}^{-1}$ na mesma ordem e no mesmo período, em Baraúna (Figura 6C e D).

Nas cultivares "IPA 11" e “Texas Grano 502" o acúmulo máximo de Mg estimado no bulbo ocorreu aos 90 DAT (99,22 mg planta $\left.^{-1}\right)$ e (21,72 mg planta $\left.^{-1}\right)$, em Petrolina (Figuras 6A e 6B) e 80 DAT (23,10 mg planta $\left.^{-1}\right)$ e 77 DAT (50,44 mg planta $\left.^{-1}\right)$, em Baraúna (Figuras 6C e D). A maior demanda ocorreu no período de 75 a 90 DAT, com taxas médias de acúmulo respectivamente para "IPA 11" e “Texas Grano 502" de 3,12 e 0,45 mg planta $^{-1} \mathrm{~d}^{-1}$ em Petrolina (Figuras 6A e B). Em Baraúna a cultivar "IPA 11" teve a maior demanda de $0,71 \mathrm{mg}$ planta $^{-1} \mathrm{~d}^{-1}$ no período de 60 a 75 DAT e 2,20 mg planta ${ }^{-1} \mathrm{~d}^{-1}$ no período de 45 a 60 DAT na “Texas Grano 502” (Figuras 6C e D).

A ordem decrescente de acúmulo para as cultivares IPA $11 \mathrm{e}$ Texas aos 90 DAT foi: Petrolina $\mathrm{Ca}>\mathrm{N}>\mathrm{K}>\mathrm{Mg}>\mathrm{P}, \mathrm{Ca}>\mathrm{K}>$ $\mathrm{N}>\mathrm{Mg}>\mathrm{P}$ e Baraúna $\mathrm{N}>\mathrm{K}>\mathrm{Ca}>\mathrm{Mg}>\mathrm{P}, \mathrm{K}>\mathrm{Ca}>\mathrm{N}>\mathrm{Mg}$ $>$ P. A cultivar IPA 11 apresentou maior acúmulo de nutrientes e o experimento realizado em Baraúna melhor desempenho em relação a Petrolina (Tabela 2). Santos et al. (2007) avaliaram o acúmulo de massa seca e o teor de nutrientes em cebola, cultivares Alfa São Francisco e Franciscana IPA 10, em Vertissolo, em Juazeiro, BA. Referidos pesquisadores concluíram que o ganho de matéria seca dos bulbos foi intensificado na metade do ciclo acompanhando a redução da matéria seca das folhas, atingindo o máximo por ocasião da colheita.

Considerando uma população de 400.000 plantas ha-1, as quantidades exportadas pelos bulbos variaram de acordo com o experimento sendo para "IPA 11" e “Texas Grano 502” em Petrolina e Baraúna (Tabela 2).

Na presente pesquisa o Ca foi, em Petrolina, o nutriente mais absorvido pelas cultivares IPA 11 e Texas Grano 502, enquanto 
A.

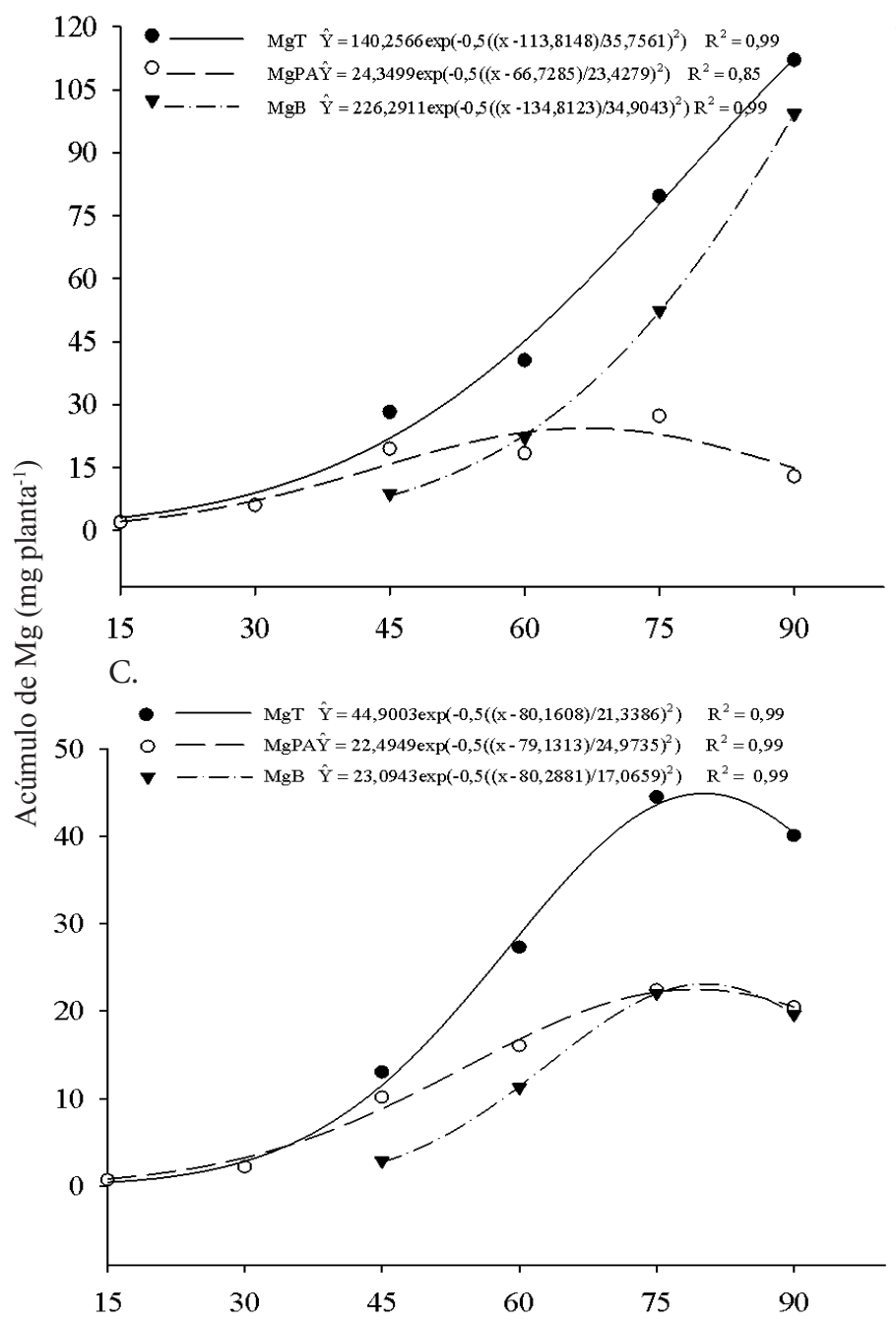

B.

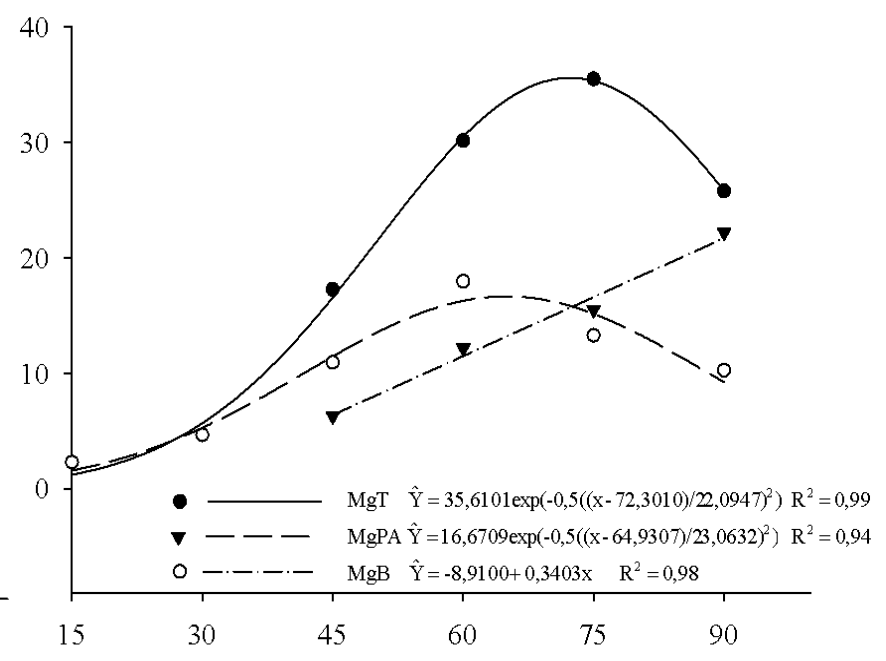

D.

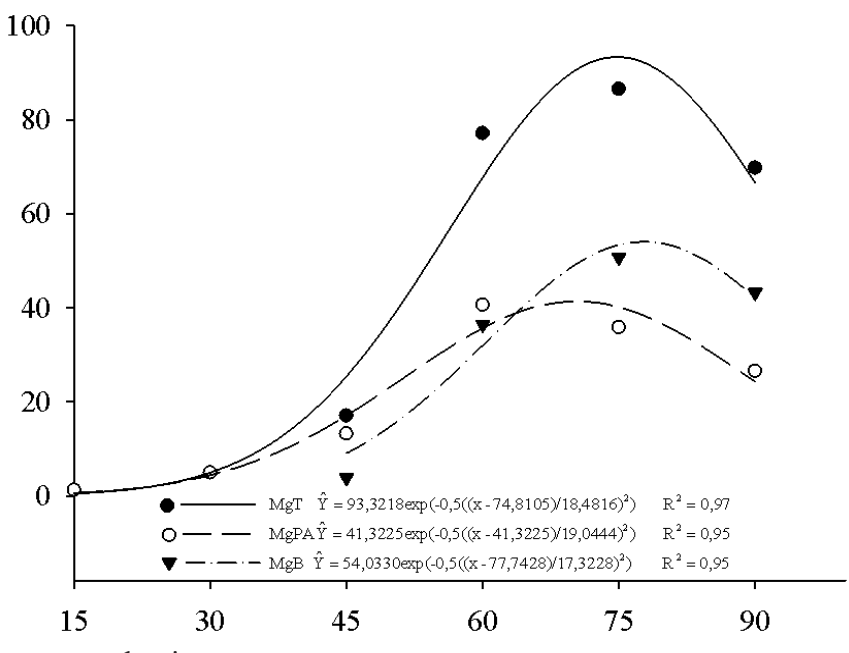

Dias após o transplantio

Figura 6. Acúmulo de Magnésio Total $(\mathrm{MgT})$, Magnésio na Parte Aérea (MgPA) e Magnésio no Bulbo (MgB) em cebola, cultivares IPA 11 (A) e Texas Grano 502 (B) em Petrolina-PE e cultivares IPA 11 (C) e Texas Grano 502 (D) em Baraúna-RN

Tabela 2. Exportação de macronutrientes pelo bulbo de cebola, cultivares IPA 11 e Texas Grano 502 em Petrolina e Baraúna

\begin{tabular}{|c|c|c|c|c|c|c|}
\hline \multirow{2}{*}{ Local } & \multicolumn{5}{|c|}{ Exportação $\left(\mathrm{kg} \mathrm{ha}^{-1}\right)$} & \multirow{2}{*}{$\begin{array}{l}\text { Prod. } \\
\left(\mathrm{t} \mathrm{ha}^{-1}\right)\end{array}$} \\
\hline & $\mathbf{N}$ & $\mathbf{P}$ & $\mathbf{K}$ & $\mathrm{Ca}$ & Mg & \\
\hline \multicolumn{7}{|c|}{ IPA 11} \\
\hline Petrolina & 101,9 & 15,1 & 87,6 & 187,6 & 39,7 & 36 \\
\hline Baraúna & 114,0 & 4,4 & 105,6 & 27,4 & 7,8 & 40 \\
\hline \multicolumn{7}{|c|}{ Texas Grano 502} \\
\hline Petrolina & 29,6 & 4,5 & 32,8 & 68,1 & 8,9 & 30 \\
\hline Baraúna & 61,8 & 5,0 & 180,6 & 73,1 & 17,3 & 35 \\
\hline
\end{tabular}

População de 400.000 plantas ha-1 $^{-1}$

que em Baraúna o K foi o mais absorvido pela "Texas Grano 502" e o N pela "IPA 11". A sequência de extração de nutrientes pelo bulbo, em Petrolina, foi $\mathrm{Ca}>\mathrm{N}>\mathrm{K}>\mathrm{Mg}>\mathrm{P}$ para "IPA 11" e $\mathrm{Ca}>\mathrm{K}>\mathrm{N}>\mathrm{Mg}>\mathrm{P}$ para "Texas Grano 502". Em Baraúna foi $\mathrm{N}>\mathrm{K}>\mathrm{Ca}>\mathrm{Mg}>\mathrm{P}$ para "IPA 11" e $\mathrm{K}>\mathrm{Ca}>\mathrm{N}>\mathrm{Mg}$ para "Texas Grano 502".

Vidigal et al. (2010a), trabalhando com cebola para a população de 1.100 .000 plantas ha $^{-1} \mathrm{e}$ produtividade de $24 \mathrm{tha}^{-1}$, concluíram que a sequência de extração de nutrientes pelo bulbo foi $\mathrm{K}>\mathrm{N}>\mathrm{Ca}>\mathrm{P}>\mathrm{Mg}$. Portanto, esses nutrientes devem ser repostos enquanto as quantidades extraídas pela parte aérea da cebola poderão ser recicladas caso a incorporação seja feita ao solo após a colheita. Dentre os fatores de manejo determinantes na produção comercial de bulbos se destaca o estabelecimento da população ideal de plantas por hectare para cada cultivar e sistema de cultivo (Baier et al., 2009).

Esta quantidade absorvida varia entre as cultivares e é distribuída de forma diferente na planta, como observado por Santos et al. (2007), nas cultivares Alfa São Francisco e Franciscana IPA 10, sendo acumulado na parte área, em ordem decrescente: $\mathrm{N}>\mathrm{Ca}>\mathrm{K}>\mathrm{P}>\mathrm{S}>\mathrm{Mg}$, enquanto nos bulbos: $\mathrm{N}>\mathrm{K}>\mathrm{Ca}>\mathrm{S}>\mathrm{P}>\mathrm{Mg}$, sendo o maior acúmulo na Alfa São Francisco.

O solo da estação experimental de Bebedouro em Petrolina foi classificado como Argissolo vermelho-amarelo eutrófico. Os Argissolos apresentam, com frequência, pedregosidade superficial no perfil do solo, podendo constituir fator limitante 
ao uso desses solos com agricultura, sobretudo com o cultivo da cebola por afetar a formação do bulbo (Santos et al., 2006). É provável que este seja o motivo pelo qual a exportação de macro e micronutrientes tenha sido menor do que em Baraúna, com reflexo na menor produtividade da cultivar Texas Grano $502\left(30 \mathrm{t} \mathrm{ha}^{-1}\right)$.

O solo de Baraúna foi classificado, como Cambissolo Háplico franco-argilo-arenoso, que apresenta boa reserva de nutrientes por ser originado de material proveniente de

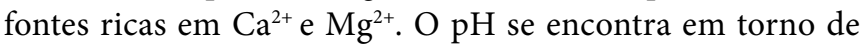
7,0 e apresenta ausência de $\mathrm{Al}^{3+}$ e teor elevado de matéria orgânica. Pode ser considerado um solo de elevado potencial agrícola, passível de que o motivo por que a exportação de $\mathrm{N}$ e K tenha sido maior que em Petrolina, com reflexo na maior produtividade da cultivar IPA $11\left(40 \mathrm{t} \mathrm{ha}^{-1}\right)$. O sistema de irrigação de Baraúna foi por gotejamento que, segundo Oliveira et al. (2008) esta técnica contribui para o aumento da produtividade das culturas reduzindo as perdas de nutrientes por lixiviação e ainda permite um controle maior da concentração de nutrientes do solo aumentando, assim, a eficiência do uso dos fertilizantes haja vista que oferece, à planta, o nutriente prontamente disponível na solução do solo para ser absorvido. Em cultivos na região nordeste a produtividade não comercial jamais ficou acima de $7 \mathrm{t} \mathrm{ha}^{-1}$ e sempre foi muito abaixo da produção comercial conforme Costa et al. (2008), Souza et al. (2008) e Resende et al. (2010).

Em Petrolina, a cultivar IPA 11 apresentou maior produtividade $\left(36 \mathrm{t} \mathrm{ha}^{-1}\right)$ em relação à Texas Grano $502(30 \mathrm{t}$ ha $^{-1}$ ), pelo fato da "IPA 11 " ter sido desenvolvida e adaptada para as condições semiáridas do nordeste brasileiro enquanto, por sua vez, a "Texas Grano 502" é um material norte-americano.

Em Petrolina a irrigação foi por microaspersão e a adubação de cobertura foi parcelada em quatro aplicações aos 20, 30, 40 e 50 dias após o transplantio. Em Baraúna utilizou-se irrigação por gotejamento e fertirrigação, dos 12 aos 60 dias após o transplantio (DAT), apresentando melhor fertilização do solo refletindo na maior produtividade da cebola.

\section{Conclusões}

1. A cebola cvs. "IPA 11 e Texas Grano 502", apresentaram crescimento inicial lento intensificando-o a partir dos 30 dias após o transplantio, DAT.

2. Maiores incrementos na massa seca total, da parte aérea e do bulbo, ocorreram no período de 60 a 75 DAT.

3. A cultivar IPA 11 apresentou maior acúmulo de massa seca, independentemente do local.

4. Os nutrientes foram absorvidos pela cebola na seguinte ordem: $\mathrm{Ca}>\mathrm{K}>\mathrm{N}>\mathrm{Mg}>\mathrm{Pe} \mathrm{Ca}>\mathrm{N}>\mathrm{K}>\mathrm{Mg}>\mathrm{P}$ para "Texas Grano 502" e "IPA 11" em Petrolina e $\mathrm{K}>\mathrm{Ca}>\mathrm{N}>\mathrm{Mg}>\mathrm{P}$ e $\mathrm{N}>\mathrm{K}>\mathrm{Ca}>\mathrm{Mg}>\mathrm{P}$ para "Texas Grano 502" e "IPA 11" em Baraúna.

5. As cultivares Texas Grano 502 e IPA 11 exportaram mais nutrientes em Baraúna.

6. As maiores produtividades foram obtidas em Baraúna com a cultivar IPA 11.

\section{Literatura Citada}

Baier, J. E.; Resende, J.T.V.; Galvão, A.G.; Battistelli, G. M.; Machado, M.M.; Faria, M. V. Produtividade e rendimento comercial de bulbos de cebola em função da densidade de cultivo. Ciência \& Agrotecnologia, v.33, p.496-501, 2009.

Braga, J. M.; Defelipo, B.V. Determinação espectofotométrica de fósforo em extratos de solos e planta. Revista Ceres, Viçosa, v.21, p.73-85, 1974.

Cavalcanti, F. J. de A. (Coord.). Recomendações de adubação para o estado de Pernambuco: 2a. aproximação. 2 ed. rev. Recife: IPA, 2008. 212p.

Costa, N. D.; Araújo, J. F.; Santos, C. A. F.; Resende, G. M.; Lima, M. A. C. Desempenho de cultivares de cebola em cultivo orgânico e tipos de solo no Vale do São Francisco. Horticultura Brasileira, v.26, p.476-480, 2008.

Echer, F. R.; Dominato, J. C.; Creste, J. E. Absorção de nutrientes e distribuição da massa fresca e seca entre órgãos de batatadoce. Horticultura Brasileira, v.27, p.176-182, 2009.

EMBRAPA - Empresa Brasileira de Pesquisa Agropecuária. Serviço Nacional de Levantamento e Conservação de Solos. Rio de Janeiro. Manual de métodos de análise de solo. Rio de Janeiro, 1997. 212p.

Ferreira, D. F. Sisvar: Um sistema computacional de análise estatística. Ciência e Agrotecnologia, v.35, p.1039-1042, 2011.

Gonçalves, P. A. S.; Wordell Filho, J. A.; Kurtz, C. Efeitos da adubação sobre a incidência de tripés e míldio e na produtividade da cultura da cebola. Revista Agropecuaria Catarinense, v.22, p.57-60, 2009.

IDEMA - Instituto de Defesa do Meio Ambient. Perfil do seu município: Baraúna. 2010. Disponível em: $<\mathrm{http}: / / \mathrm{www}$. idema.rn.gov.br/governo/secretarias/idema/perfil/Barauna. Acesso em: out. de 2012.

Jandel Scientific. Table curve: curve fitting software. Corte Madera, CA: Jandel Scientific, 1991. 280p.

Kurtz, C.; Ernani, P. R. Produtividade de cebola influenciada pela aplicação de micronutrientes. Revista Brasileira de Ciência do Solo, v.34, p.133-142, 2010.

May, A.; Cecílio Filho, A. B.; Porto, D. R. de Q.; Vargas, P. F.; Barbosa, F. C. Acúmulo de macronutrientes por duas cultivares de cebola produzidas em sistema de semeadura direta. Bragantia, v.67, p.507-512, 2008.

Oliveira, A. F.; Medeiros, J. F. de; Lima, C. J. G. S.; Dutra, I.; Oliveira, M. K. T. Eficiência agronômica da fertirrigação nitrogenada e potássica na cultura do meloeiro nas condições do semi-árido nordestino. Revista Caatinga, v.21, p.5-11, 2008.

Pereira, V. da C.; Espínola Sobrinho, J.; Oliveira, A. D. de; Vieira, R. Y. M.; Melo, T. K. de; Melo, S. B; Silva, F. G. Influência dos eventos El Niño e La Niña na precipitação pluviométrica de Mossoró-RN. In: Congresso Brasileiro de Meteorologia, 16. A Amazônia e o Clima Global. Belém, Anais...2010. CD-Rom

Porto, D. R. de Q. Crescimento e acúmulo de macronutrientes pela cebola, em cultura estabelecida por semeadura direta. Jaboticabal: UNESP, 2005. 33p. Dissertação Mestrado 
Porto, D. R. de Q.; Cecílio Filho, A. B.; May, A.; Barbosa, J. C. Acúmulo de macronutrientespela cultivar de cebola Optima estabelecida por semeadura direta. Horticultura Brasileira, v.24, p.470-475, 2006.

Pôrto, D. R. de Q.; Cecílio Filho, A. B.; May, A.; Vargas, P. F. Acúmulo de macronutrientes pela cultivar de cebola "Superex" estabelecida por semeadura direta. Ciência Rural, v.37, p.949-955, 2007.

Resende, J. T. V.; Marchese, A.; Camargo, L. K. P.; Marodin, J. C.; Camargo, K. P.; Morales, R. G. F. Produtividade e qualidade pós-colheita de cultivares de cebola em sistemas de cultivo orgânico e convencional. Bragantia, v.69, p.305$311,2010$.

Rodolfo Júnior, F.; Cavalcante, L. F; Buriti, E. S. Crescimento e produção do maracujazeiro-amarelo em solo com biofertilizantes e adubação mineral com NPK. Revista Caatinga, v.22, p.134-145, 2008.

Sá, J. R.; Oliveira, A. E. S.; Medeiros, J. F. de; Nogueira, N. W.; Silva, C. B. Interação da adubação organo-mineral nos atributos químicos do solo na cultura do melão em Mossoró - RN - Brasil. Revista Verde de Agroecologia e Desenvolvimento Sustentável, v.5, p.89-100, 2010.

Santos, C. A. F.; Oliveira, V. R. Melhoramento genético de cebola no Brasil: Avanços e desafios. Horticultura Brasileira 29. S5727-S5743, 2011.
Santos, E. E. F.; Fernandes, D. M.; Silva, D. J.; Bull, L. T. Acúmulo de macronutrientes por cultivares de cebola, em um vertissolo no médio São Francisco. In: Congresso Brasileiro de Ciência do Solo, 31., 2007, Gramado. Conquistas e desafios da ciência do solo brasileira: anais. Porto Alegre: SBCS, 2007. 1 CD-Rom

Santos, H. G.; Jacomine, P. K. T.; Anjos, L. H. C.; Oliveira, V. A.; Oliveira, J. B.; Coelho, M. R.; Lumbreras, J. F.; Cunha, T. J. F. (Ed). Sistema brasileiro de classificação de Solos. 2. ed. Rio de Janeiro: Embrapa Solos, 2006, 306p.

Sousa, G. B.; Cavalcante, L. F.; Cavalcante, I. H. L.; Cavalcante, M. Z. B.; Nascimento, J. A. Salinidade do substrato contendo biofertilizante para formação de mudas de maracujazeiro irrigado com água salina. Revista Caatinga, v.21, p.172$180,2008$.

Souza, J. O.; Grangeiro, L. C.; Santos, G. M.; Costa, N. D.; Santos, C. A. F; Nunes, G. H. S. Avaliação de genótipos de cebola no Semi-Árido Nordestino. Horticultura Brasileira, v.26, p.97-101, 2008.

Vidigal, S. M.; Moreira M. A.; Pereira, P. R. G. Crescimento e absorção de nutrientes pela planta de cebola cultivada no verão por semeadura direta e por transplantio de mudas. Bioscience Journal, v.26, p.59-70, 2010a.

Vidigal, S. M.; Sediyama, M. A. N.; Pedrosa, M. W.; Santos, M. R. Produtividade de cebola em cultivo orgânico utilizando composto à base de desejos de suínos. Horticultura Brasileira, v.28, p.168-173, 2010b. 